\title{
Over-expression of gluconic acid in Aspergillus oryzae RP-21 mutants generated by a random mutagenesis approach
}

\author{
Sunhare Raksha $\cdot$ Sharmila Srinivasan $\cdot$ \\ Garima Prasant $\cdot$ Rajagopalan Prabu
}

Received: 20 December 2011/ Accepted: 7 February 2012/Published online: 2 March 2012

(C) The Author(s) 2012. This article is published with open access at Springerlink.com

\begin{abstract}
Random mutagenesis with $N$-methyl- $N^{\prime}$ nitro$N$-nitrosoguanidine (NTG) was used to mutate Aspergillus oryzae RP-21 to develop high gluconic acid-producing mutants. Forty mutant colonies (designated as A. oryzae strains RP-NTG-01 to RP-NTG-40) screened for gluconic acid, glucose dehydrogenase and glucose oxidase production using a 12-well plate method showed that 17 strains (positive mutants) produced high concentrations of these three products, whereas 12 strains (negative mutants) showed low concentrations and the remaining 11 strains (non-mutants) did not produce any of the three products. Detailed studies of $A$. oryzae RP-NTG-12, a positive mutant, produced gluconic acid of up to $72 \mathrm{~g} / \mathrm{L}$ in batch fermentation, which was a 2.4-fold increase in yield to that of the strain and as expected it also possessed higher activities of cell-bound glucose dehydrogenase and glucose oxidase, key enzymes of the multi-functional gluconic acid synthesis pathway. We discuss changes in the cell-bound enzyme activities of the mutants and the wild type and
\end{abstract}

S. Raksha

Institute of Bioscience, Universiti Putra Malaysia,

43400 UPM Serdang, Selangor, Malaysia

S. Srinivasan

School of Chemical and Biotechnology, SASTRA University,

Thanjavur 613401, India

G. Prasant

Amity Institute of Biotechnology, Jaipur 302006, India

R. Prabu $(\bowtie)$

Department of Bioprocess Technology, Faculty

of Biotechnology and Biomolecular Sciences,

Universiti Putra Malaysia, 43400 UPM Serdang,

Selangor, Malaysia

e-mail: bioprabhu21@gmail.com speculate on a mechanism for this increase. The mutant strain, A. oryzae RP-NTG-12, and the random mutagenesis method used to increase bioproducts have a good potential for developing fermentation processes to an industrial scale as demonstrated by this study.

Keywords Aspergillus. oryzae . $N$-Methyl- $N^{\prime}$ nitro- $N$-nitrosoguanidine (NTG) .

Mutation - Gluconic acid

\section{Introduction}

Though gluconic acid (pentahydroxycaproic acid) and its salts have many applications in the food, medical, beverage and textile industries (Lee et al. 1996), its one of the more outstanding applications is use in solubilization of phosphate and as an additive for enhancing the resistance and stability of cement under extreme climatic conditions in the construction industry (Anastassiadis and Rehm 2006). Gluconic acid or sodium gluconate can be produced by chemical, electrochemical, biochemical and bioelectrochemical methods (Lee et al. 1999). Due to the high production costs and low yields by these processes, its commercialization has not been successfully achieved (Lee et al. 1999). The current preferred economical production of gluconic acid is by submerged fermentation with Aspergillus niger, in which glucose is converted at a rate of $15 \mathrm{~g} / \mathrm{L} / \mathrm{h}$. This process involves fed-batch cultivation, in which glucose is added intermittently at $34{ }^{\circ} \mathrm{C}$ and the $\mathrm{pH}$ is maintained at $6.0-6.5$ neutralization by sodium hydroxide. Several variations to this process have also been described (Lee et al. 1998). In addition, gluconic acid-producing microorganisms, such as Aureobasidium pullulan (Anastassiadis and Rehm 2006), Pseudomonas fluorescens (Werra et al. 2009), Aspergillus 
terreus (Dowdells et al. 2010) and Enterobacter intermedium (Gomez et al. 2010) have also been isolated. However, the results of gluconic acid production have met with mixed results. An alternate approach to the isolation of new strains is to mutate a promising strain and screen for mutants that are better producers (Prabu et al. 2011). Nmethyl- $N^{\prime}$-nitro- $N$-nitrosoguanidine (NTG) and ultraviolet (UV) radiation have been successfully used to enhance the industrial production of lipase (Bapiraju et al. 2004), xylitol (Rao et al. 2006), L-DOPA (Haq and Ali 2006) and kojic acid (Prabu et al. 2011). Prabu et al. (2011) have suggested that random mutagenesis approach for industrial strain improvement is simple, easy and effective when compared with recombination technologies and have therefore advocated this approach for generating mutants. The aim of the study reported here was to use random mutagenesis on the wild-type $A$. oryzae and generate mutants with improved gluconic acid yields, and to evaluate the performance of these mutants in terms of the yield of gluconic produced per carbon of glucose consumed in shake flask experiments.

\section{Materials and methods}

The steps involved in generating mutants from the parent wild-type strain $A$. niger RP-2 by random mutagenesis, screening of high gluconic acid-producing mutants and studies on the enzymes of the gluconic acid pathway are illustrated in Fig. 1.

\section{Microorganism}

The parent wild-type strain $A$. oryzae RP-21 was isolated from infected pomegranate pollen (Punica granatum L) by using the monospore isolation method as reported previously (Prabu et al. 2011).

Mutation and isolation of high-level gluconic acidproducing mutants

Monospores were produced by repeated sub-culturing of $A$. oryzae RP-21 on Potato Dextrose Agar (PDA) slants at $30{ }^{\circ} \mathrm{C}$ for $120 \mathrm{~h}$. Initially, 20-30 single colonies were isolated and sub-cultured for monospores. Sterile $0.001 \%$ (v/v) Tween-80 was added and the slants shaken for 5 min in order to harvest the spores. The harvested spores were then washed three times with $0.5 \mathrm{M}$ phosphate buffer $(\mathrm{pH}$ 7.0), the spore suspension serially diluted with phosphate buffer and sub-cultured onto PDA agar plates for the isolation of single colonies. The standardized spore suspension (approximately $1 \times 10^{7}$ spores/mL medium) was used to screen for gluconic acid production using the 24-well plate method $(2 \mathrm{~mL})$ and/or shake flask cultures $(150 \mathrm{~mL})$. The highest gluconic acid-producing culture derived from the monospore suspension was selected and mutated with
Fig. 1 A summary of the steps, procedures and outcomes on the random mutagenesis studies of Aspergillus niger RP-21

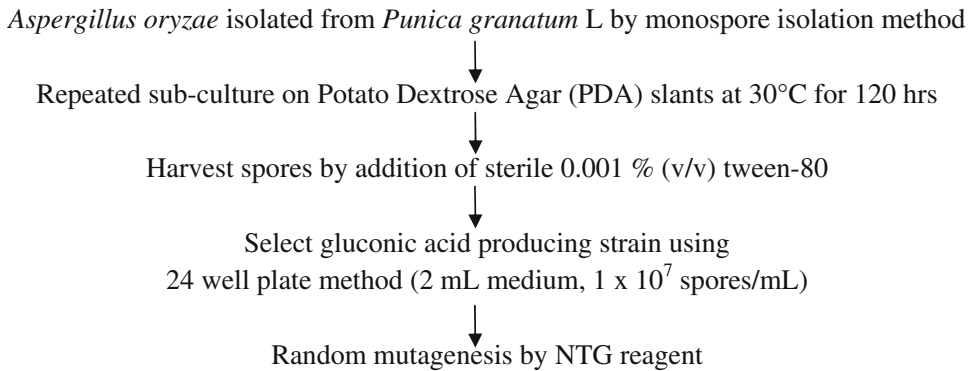

(Add $1.0 \mathrm{mg} / \mathrm{mL}$ NTG in $5 \mathrm{~mL}\left(1 \times 10^{7}\right.$ spores $\left./ \mathrm{mL}\right)$ of monospore A. oryzae RP 21 suspension) Incubate suspension at $30^{\circ} \mathrm{C} ; 200 \mathrm{rpm}, 15-60 \mathrm{~min}$ 1

Wash \& serially dilute the suspension with $0.2 \mathrm{M}$ phosphate buffers ( $\mathrm{pH} 7.0$ ) $\downarrow$

Mutant isolated by using the monospore isolation method (40 colonies designated A. oryzae RP-NTG-01 to RP-NTG-40 selected) Mutants screened for improved gluconic acid production \& associated enzymes using 12 well plate fermentation $\left(5 \mathrm{~mL}\right.$ medium, $1 \times 10^{7}$ spores $\left./ \mathrm{mL}\right)$

$17,12 \& 11$ mutants identified as positive-, 12 negative- and 11 non-mutants $\downarrow$

A. oryzae RP-NTG-12 best gluconic acid producer studied using shake flask fermentation ( $150 \mathrm{~mL}$ medium in $500 \mathrm{~mL}$ flask, $30^{\circ} \mathrm{C}, 200 \mathrm{rpm}$ ) 
$N$-methyl- $N^{\prime}$ nitro- $N$-nitrosoguanidine (NTG) as described by Prabu et al. (2011). One $\mathrm{mL}$ of NTG $(1.0 \mathrm{mg} / \mathrm{mL})$ was added to $5 \mathrm{~mL}$ of the gluconic acid-producing monospore suspension $\left(1 \times 10^{7}\right.$ spores $\left./ \mathrm{mL}\right)$ in a $50-\mathrm{mL}$ sterile Falcon tube. The mixture was incubated at $30^{\circ} \mathrm{C}$ in a rotary shaker, agitated at $200 \mathrm{rpm}$ for different time intervals (15, 30,45 and $60 \mathrm{~min}$ ), washed three times with $0.2 \mathrm{M}$ phosphate buffer ( $\mathrm{pH} 7.0$ ), subsequently serially diluted with the same buffer and sub-cultured onto PDA agar plates. Single well-isolated colonies that developed were selected and further sub-cultured onto solid PDA agar plates with the conditions described above.

Fermentation and extraction of enzymes from mycelia

Forty single well-isolated colonies (designated A. oryzae RP-NTG-01 to RP-NTG-40) were selected by the monospore isolation method and used to determine their ability to produce gluconic acid. Spore suspensions $\left(1 \times 10^{7}\right.$ spores $\left./ \mathrm{mL}\right)$ of $A$. oryzae mutant strains designated RP-NTG-01 to RP-NTG-40 and the parent wild type were initially screened for gluconic acid production using a 12-well plate fermentation method. In this method, $5 \mathrm{~mL}$ of medium [(g/L) glucose 120; yeast extract 40; $\mathrm{KH}_{2} \mathrm{PO}_{4} 1.0 ; \mathrm{K}_{2} \mathrm{HPO}_{4} 1.0 ; \mathrm{MgSO}_{4} 0.5 ; \mathrm{NaCl} 1.5 ; \mathrm{Na} \mathrm{SO}$ 1.5 ; $\mathrm{pH} 4.0$ ] was inoculated with $0.1 \mathrm{~mL}$ of spore suspension and incubated at $30{ }^{\circ} \mathrm{C}$ for $240 \mathrm{~h}$. Subsequently, the best gluconic acid producer was tested further using batch fermentation in $500-\mathrm{mL}$ shake flasks containing $150 \mathrm{~mL}$ of medium. In this case, the flasks were inoculated with $1.5 \mathrm{~mL}$ spore suspension $\left(1 \times 10^{7}\right.$ spores $\left./ \mathrm{mL}\right)$, incubated at $30{ }^{\circ} \mathrm{C}$ on a rotary shaker and agitated at $200 \mathrm{rpm}$ to initiate fermentation. The fermentation broth was filtered through a vacuum filter at $4{ }^{\circ} \mathrm{C}$, the mycelia washed two to three times with an equal amount of phosphate buffer $(\mathrm{pH} 7,0.01 \mathrm{M})$ and the weight of the cell paste determined. Then, $20 \mathrm{~mL}$ of ice-chilled phosphate buffer ( $\mathrm{pH} 7.2,0.1 \mathrm{M}$ ) was added to approximately $20 \mathrm{~g} \mathrm{f}$ mycelia and the cells lysed by ultrasonication (Elyas et al. 2010). The homogenate was centrifuged (Kubota model 2010) at $4,000 \times g$ for $10 \mathrm{~min}$ at $4{ }^{\circ} \mathrm{C}$ and the clear supernatant was used to determine glucose, gluconic acid, glucose oxidase and glucose dehydrogenase.

Analytical methods

The concentration of gluconic acid was estimated using an HPLC (Lee et al. 1999), glucose concentration was determined by dinitrosalicylic acid (DNS) as described by Miller et al. 1960), glucose dehydrogenase activity was assayed as per the method of Lamble et al. (2003), and glucose oxidase enzyme activity was assayed according to Bergmeyer et al. (1974).

\section{Results and discussion}

Initial screening of the 40 mutants of $A$. oryzae RP-21 (designated $A$. oryzae strains RP-NTG-01 to RP-NTG-40) using the 12-well plate method showed that 17 strains (positive mutants) produced high concentrations of gluconic acid, 12 strains (negative mutants) showed poor gluconic acid production and the remaining 11 strains (non-mutants) were unable to produce gluconic acid. These results demonstrate that random mutagenesis using NTG can be used to improve the ability of $A$. oryzae RP-21 to produce gluconic acid. NTG stimulates a relatively wide spectrum of mutations by alkylating pyrimidines and purines, of which the $\mathrm{G}: \mathrm{C} \rightarrow \mathrm{A}: \mathrm{T}$ transition is more prevalent than the $\mathrm{A}: \mathrm{T} \rightarrow \mathrm{G}: \mathrm{C}$ transitions (Prabu et al. 2011). This type of mutation could damage the genome of the gluconic acid-producing fungus (A. oryzae RP-21) and hence alter the gluconic acid synthesis enzymes at a transcription and/ or translation level. Such alterations could lead to an increase in enzyme production or improve the active site for the binding of the substrate for conversion to the target metabolite (Gunka et al. 2010).

Of the 17 strains of positive mutants, A. oryzae RP-NTG-12 was the highest gluconic acid producer and hence this strain was tested further. A comparison of the positive mutant $A$. oryzae RP-NTG-12, the negative mutant A. oryzae RP-NTG-31 and the wild-type A. oryzae RP-21 is shown in Table 1. The results demonstrate that two enzymes, namely glucose dehydrogenase and glucose oxidase, had higher activities in the positive mutant in comparison to the negative mutant or the wild-type strain and it also produced higher concentrations (2.4-fold) of gluconic acid. In addition, a number of other positive mutants that had been assayed also showed elevated levels (1.6- to 1.8-fold) of these two enzymes (data not shown). This would suggest that these two enzymes could play an important role in gluconic acid synthesis.

The time course study for gluconic acid production in batch fermentation by the positive mutant $A$. oryzae RP-NTG-12 and the wild-type $A$. oryzae RP21 is shown in Fig. 2. During exponential growth of the positive mutant A. oryzae RP-NTG-12, the concentration of gluconic acid increased with a concomitant decrease in glucose concentration. This suggested that glucose was converted to gluconic acid. The maximum concentration of gluconic acid $(72 \pm 0.6 \mathrm{~g} / \mathrm{L})$ was achieved after about $432 \mathrm{~h}$ of incubation. There was no further increase in gluconic acid production in the stationary phase, even though some glucose still remained. This result demonstrated that the nongrowing mycelia were unable to convert glucose into gluconic acid, and therefore active growth was necessary for the conversion of glucose to gluconic acid. In contrast, the wild-type $A$. oryzae RP21 produced the same amount of 
Table 1 Performance of gluconic acid (GA) producing mutants and the parent strain

\begin{tabular}{|c|c|c|c|c|c|c|c|c|}
\hline $\begin{array}{l}\text { A. niger } \\
\text { strain }\end{array}$ & $\begin{array}{l}\text { Fermentation } \\
\text { time (h) }\end{array}$ & $\begin{array}{l}\text { Maximum } \\
\text { biomass. } \\
(\mathrm{g} / \mathrm{L})\end{array}$ & $\begin{array}{l}\text { Maximum } \\
\text { GA conc. } \\
\text { (g/L) }\end{array}$ & $\begin{array}{l}\mathrm{GA}^{\mathrm{a}} \text { yield } \\
\text { based on } \\
\text { glucose } \\
\text { consumed }(\mathrm{g} / \mathrm{g})\end{array}$ & $\begin{array}{l}\text { Cell yield } \\
\text { based on glucose } \\
\text { consumed }(\mathrm{g} / \mathrm{g})\end{array}$ & $\begin{array}{l}\mathrm{GA}^{\mathrm{a}} \text { based } \\
\text { on cell } \\
\text { mass }(\mathrm{g} / \mathrm{g})\end{array}$ & $\begin{array}{l}\text { Glucose } \\
\text { dehydrogenase } \\
\text { activity } \\
(\mathrm{U} / \mathrm{mL})\end{array}$ & $\begin{array}{l}\text { Glucose } \\
\text { oxidase } \\
\text { activity } \\
\text { (U/mL) }\end{array}$ \\
\hline RP-21 (parent strain) & 432 & $20 \pm 0.8$ & $30 \pm 0.5$ & $0.33 \pm 0.01$ & $0.66 \pm 0.02$ & $1.5 \pm 0.8$ & $8.9 \pm 0.5$ & $3.6 \pm 0.2$ \\
\hline $\begin{array}{l}\text { RP-NTG-12 (positive } \\
\text { mutant) }\end{array}$ & 432 & $20 \pm 0.6$ & $72 \pm 0.6$ & $0.65 \pm$ & 0.02 & $3.6 \pm 0.6$ & $22 \pm 0.8$ & $9.1 \pm 0.3$ \\
\hline $\begin{array}{l}\text { RP-NTG-31 (negative } \\
\text { mutant) }\end{array}$ & 500 & $22 \pm 0.6$ & $10 \pm 0.5$ & $0.14 \pm 0.02$ & $0.3 \pm 0.005$ & $0.45 \pm 0.6$ & $3.1 \pm 0.3$ & $1.2 \pm 0.1$ \\
\hline
\end{tabular}

${ }^{a}$ Gluconic acid

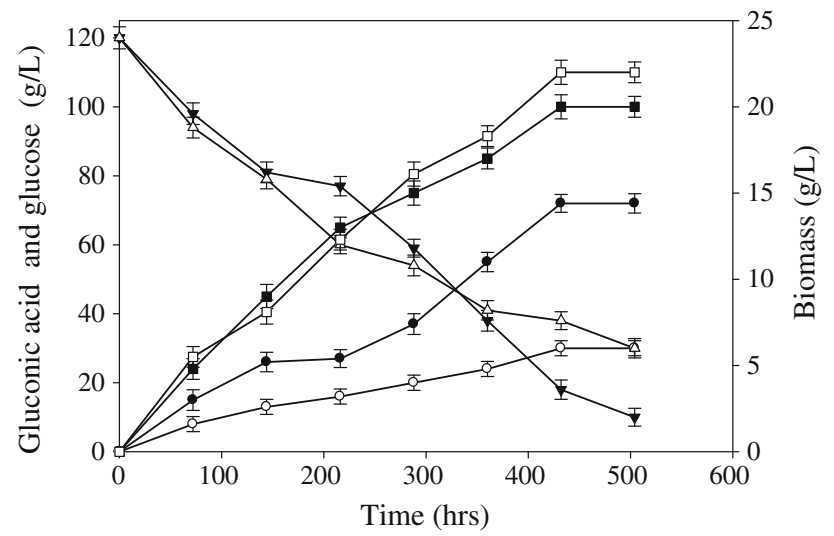

Fig. 2 Time course of the growth of the positive mutant A. oryzae RP-NTG-12 with respect to biomass production (filled squares), glucose utilization (filled inverted triangles) and gluconic acid production (filled circles) in comparison to that of the wild-type A. oryzae RP-21's biomass production (open squares), glucose utilization (open triangles) and gluconic acid production (open circles)

biomass, but only $10 \pm 0.5 \mathrm{~g} / \mathrm{L}$ gluconic acid even after consuming $70 \%$ of the total glucose, suggesting that the glucose was converted into biomass and not gluconic acid. Similarly, the stationary phase mycelium was unable to convert the glucose to gluconic acid.

The profiles of the two enzymes, glucose dehydrogenase and glucose oxidase, for the positive mutant $A$. oryzae RPNTG-12 and the negative mutant $A$. oryzae RP-NTG-31 during growth is shown in Fig. 3. The concentration of glucose dehydrogenase was the highest $(20 \pm 0.8 \mathrm{U} / \mathrm{mL})$ between 350 and $450 \mathrm{~h}$ with the positive mutant $A$. oryzae RP-NTG-12 and was 2.4-fold higher than that of the wildtype strain $(8.9 \pm 0.5 \mathrm{U} / \mathrm{mL})$. Similarly, the glucose oxidase concentration $(9.1 \pm 0.3 \mathrm{U} / \mathrm{mL})$ peaked between 350 and $450 \mathrm{~h}$ and was also approximately 2.5 -fold higher than the strain $(3.1 \pm 0.3 \mathrm{U} / \mathrm{mL})$. Higher concentrations of glucose dehydrogenase and glucose oxidase during fermentation with the positive mutant, A. oryzae RP-NTG-12, as compared to the strain is linked to the production of the higher concentrations of gluconic acid. In addition, the negative mutant, A. oryzae RP-NTG-31, had low

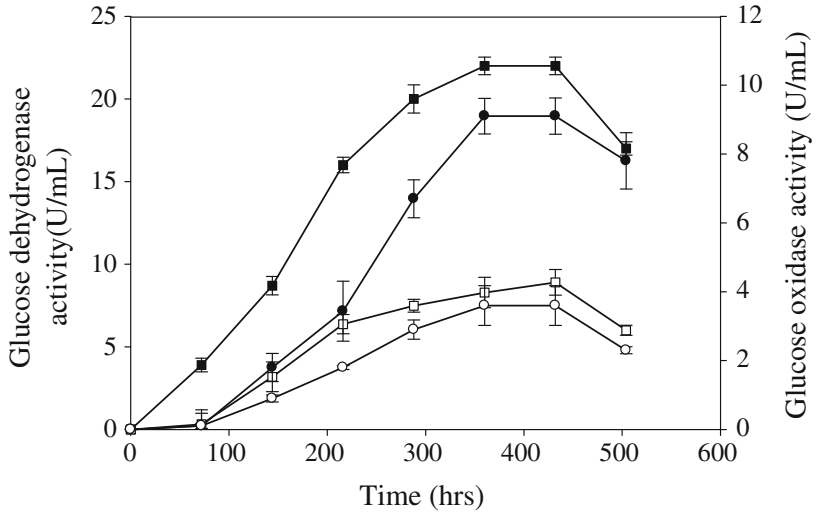

Fig. 3 Time course of the positive mutant A. oryzae RP-NTG-12 with respect to the production of glucose oxidase (filled circles) and glucose dehydrogenase (open squares) activities in comparison to that of the wild-type A. oryzae RP-21's glucose oxidase (open circles) and glucose dehydrogenase (filled squares) activities

concentrations of glucose dehydrogenase and glucose oxidase and also produced low concentrations of gluconic acid as compared to the strain, while the cell mass remained the same. We therefore speculate that the suppressor gene of the enzymes involved in gluconic acid synthesis in the positive mutant $A$. oryzae RP-NTG-12 could have been mutated either by a frame shift mutation producing an inactive protein or by a base change (substitution) which could lead to a change in the amino acid composition and, therefore, a change in the conformation of this protein. This would result in the suppressor protein not being able to regulate the feedback mechanism of the enzymes involved in gluconic acid synthesis and thereby resulting in higher enzyme secretion. More work will need to be undertaken to determine the basis of the improvement in gluconic acid production by the positive mutant $A$. oryzae RP-NTG-12.

This simple approach of random mutagenesis to improve industrial strain development process has more advantages as compared to fermentation optimization strategies (Cheema et al. 2002), which usually involve a multitude of steps such as use of cheaper carbohydrate sources (Singh and Singh 2006), feedback regulation by $\mathrm{pH}$ 
adjustments (Dowdells et al. 2010), the use of fungal spores as biocatalysts (Ramachandran et al. 2007) and solid-state fermentation (Sharma et al. 2008).

\section{Conclusion}

Our study has demonstrated that random mutagenesis with NTG can be successfully used to improve gluconic acid production. The positive mutant, A. oryzae RP-NTG-12, derived from random mutagenesis, was capable of producing gluconic acid up to a final concentration of $72 \mathrm{~g} / \mathrm{L}$ in shake flask batch fermentation. This type of strain development is simple, reproducible and can be useful for the development of fermentation process for any industrial product.

Open Access This article is distributed under the terms of the Creative Commons Attribution License which permits any use, distribution and reproduction in any medium, provided the original author(s) and source are credited.

\section{References}

Anastassiadis S, Rehm HJ (2006) Continuous gluconic acid production by Aureobasidium pullulans with and without biomass retention. E J Biotech 9:494-504

Bapiraju KVVSN, Sujatha P, Ellaiah P, Ramana T (2004) Mutation induced enhanced biosynthesis of lipase. African J Biotechnol 3:618-621

Bergmeyer HU, Gawehn K, Grassl M (1974) Glucose-6-phosphate dehydrogenase from yeast. In: Bergmeyer HU (ed) Methods of enzymatic analysis, 2nd edn. Academic Press Inc, New York, pp 457-458

Cheema JJ, Sankpal NV, Tambe SS, Kulkarni BD (2002) Genetic programming assisted stochastic optimization strategies for optimization of glucose to gluconic acid fermentation. Biotechnol Prog 18:1356-1365

Dowdells C, Jones RL, Mattey M, Bencina M, Legisa M, Mousdale DM (2010) Gluconic acid production by Aspergillus terreus. Lett Appl Microbiol 51:252-257

Elyas KK, Mathew A, Sukumaran RK, Ali PP, Sapna K, Kumar SR, Mol KR (2010) Production optimization and properties of beta glycosidase from a marine fungus Aspergillus-SA 58. New Biotech 27:347-351
Gomez W, Buela L, Castro LT, Chaparro V, Ball MM, Yarzabal LA (2010) Evidence for gluconic acid production by Enterobacter intermedium as an efficient strategy to avoid protozoan grazing. Soil Biol Biochem 42:822-830

Gunka K, Newman JA, Commichau FM, Herzberg C, Rodrigues C, Lorraine H (2010) Functional dissection of a trigger enzyme: mutations of the Bacillus subtilis glutamate dehydrogenase RocG that affect differentially its catalytic activity and regulatory properties. J Mol Bio 400:815-827

Haq I, Ali S (2006) Mutation of Aspergillus Oryzae for improved production of 3, 4 dihydroxy phenyl-L-alanine (L-DOPA) from L-tyrosine. Brazilian J Microbiol 37:78-86

Lamble HJ, Heyer NI, Bull SD, Hough DW, Danson MJ (2003) Metabolic pathway promiscuity in the Archaeon sulfolobus solfataricus revealed by studies on glucose dehydrogenase and 2-keto-3-deoxygluconate aldolase. J Biol Chem 278:3406634072

Lee HC, Chung BW, Kim CY, Kim DH, Ra BK (1996) The production of sodium gluconate by Aspergillus niger. Kor $\mathrm{J}$ Biotechnol Bioeng 11:65-70

Lee SH, Lee HC, Kim DH, Yang MS, Chung BW (1998) Overproduction of sodium gluconate using the recombinant Aspergillus niger. Kor J Biotechnol Bioeng 13:214-219

Lee SY, Park BS, Kim JH, Kim BG, Kim D (1999) Sodium gluconate production by Aspergillus niger with intermittent broth replacement. Biotechnol Bioprocess Eng 4:101-105

Miller GL, Blum R, Glennon WE, Burton AL (1960) Measurement of carboxymethyl-cellulase activity. Anal Biochem 1:127-132

Prabu R, Mohamad R, Md Shah UK, Ariff AB (2011) Improvement of Aspergillus flavus Link S44-1 using random mutational method for kojic acid production. Minerva Biotecnol 23:83-91

Ramachandran S, Fontanille P, Pandey A, Larroche C (2007) Spores of Aspergillus niger as reservoir of glucose oxidase synthesized during solid-state fermentation and their use as catalyst in gluconic acid production. Lett Appl Microbiol 44:155-160

Rao RS, Jyothi CP, Prakasham RS, Rao CS, Sarma PN, Rao LV (2006) Strain improvement of Candida Tropicalis for the production of xylitol: biochemical and physiological characterization of wild-type and mutant strain CT-OMV5. J Microbiol 44:113-120

Sharma A, Vivekanand V, Singh RP (2008) Solid-state fermentation for gluconic acid production from sugarcane molasses by Aspergillus niger ARNU-4 employing tea waste as the novel solid support. Bioresour Technol 99:3444-3450

Singh OV, Singh RP (2006) Bioconversion of grape must into modulated gluconic acid production by Aspergillus niger ORS4.410. J Appl Microbiol 100:1114-1122

Werra P, Tarr MP, Keel C, Maurhofer M (2009) Role of gluconic acid production in the regulation of biocontrol traits of pseudomonas fluorescens CHA0. Appl Enviorn Microb 75:4162-4174 